\title{
LEÓN Y LA REAL ACADEMIA ESPAÑOLA. ACADÉMICOS LEONESES EN EL PRIMER SIGLO DE VIDA DE LA INSTITUCIÓN.
}

MARTA PRIETO SARRO1

IES Ramiro II

\section{Resumen}

Desde su fundación, nueve leoneses han sido académicos de número de la Real Academia Española. Cuatro de ellos en el primer siglo de vida de la institución.

Palabras clave: Real Academia Española. Provincia de León. Juan de Ferreras. Alonso Rodríguez Castañón. Pedro Álvarez Acevedo. Casimiro Flórez Canseco.

\begin{abstract}
The province of León has contributed with nine members to Real Academia Española. Four of them in the first century of the Institution.
\end{abstract}

Keywords: Real Academia Española. Province of León. Juan de Ferreras. Alonso Rodríguez Castañón. Pedro Álvarez Acevedo. Casimiro Flórez Canseco.

\section{La fundación de la Real Academia Española y Juan de Ferreras.}

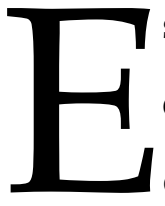
s de sobra conocido, pero no por ello debe dejar de mencionarse, que entre el grupo de intelectuales formado a partir de 1711 alrededor de la persona de Juan Manuel Fernández Pacheco, marqués de Villena, que regresa a España desde Italia tras un doloroso cautiverio ${ }^{2}$, se encontraba un prócer leonés: el bañezano Juan de Ferreras. Él será uno de los cofundadores de la Real Academia

\footnotetext{
${ }^{1}$ Profesora del IES Ramiro II (León). Correo-e: mprietosarro@gmail.com. Recibido 06-02-2009; segunda versión: 12-05-2009.

2 El marqués de Villena, virrey de Sicilia y Nápoles, fue capturado en Gaeta en 1707 y permaneció encarcelado hasta 1711, fecha en que fue canjeado.
} 
Española y, evidentemente, uno de sus ocho primeros académicos 3 : aquellos pilares fundamentales de una institución que echa a andar de forma efectiva el tres de agosto de 1713, fecha en la que se levanta la primera acta. Para entonces ya estaban incorporados a ella otros tres, Francisco Pizarro, José de Solís y Gante y Vincencio Squarzafigo, pues este último es elegido secretario al tiempo que se distingue al marqués de Villena como director.

Juan de Ferreras había nacido, efectivamente, en La Bañeza, en cuya iglesia de Santa María fue bautizado, según recoge Marcos Segovia (1957: 34), el día 18 de junio de 1652. Era hijo de Antonia García y de Antonio Ferreras, escribano de número de la villa y su ayuntamiento, cuya profesión, según han hecho notar varios autores ${ }^{4}$, nos le encuadra fehacientemente en una clase social determinada y clara. De ahí que no cause extrañeza su formación pues si, como es habitual no constan sus primeros estudios (sin duda realizados en su lugar de nacencia), sí tenemos conocimiento de sus siguientes etapas: primero el colegio de los jesuitas de Monforte de Lemos (Orense), después el famoso convento dominico de Trianos (León) ${ }^{5}$, más tarde el colegio San Gregorio de Valladolid, donde cursa Teología y, finalmente, la Universidad de Salamanca.

\footnotetext{
${ }^{3}$ Fueron, además del citado Juan Manuel Fernández Pacheco, al que con justa razón se considera fundador de la Real Academia Española, Gabriel Álvarez de Toledo, Andrés González Barcia, Fray Juan Interián de Ayala, los jesuitas Bartolomé Alcázar y José Casani y, por último, Antonio Dongo Barnuevo.

${ }^{4}$ Abordan la figura de Juan de Ferreras, entre otros, José Marcos Segovia (1957), Policarpo Mingote y Tarazona (1978) y Francisco Martínez García (1982). Interesa también el Elogio histórico, que fue pronunciado a su muerte por encargo de la Academia por Blas Antonio de Nassarre.

${ }^{5}$ El monasterio de Santa María la Real de Trianos fue fundado en el siglo XII por la familia de los Tello Téllez de Meneses en su dominio de Trianos. Lo cedieron a los canónigos regulares de San Agustín a los que relevaron en 1520 los dominicos que hicieron del monasterio un centro de estudios de renombre agregado a un colegio universitario y con facultad de conceder grados académicos. El estudio de Trianos, al que se habían aplicado rentas procedentes del priorato de San Miguel de Escalada, desapareció al ser desamortizados los bienes del convento y exclaustrados sus monjes. Sus ruinas se encuentran, en un abandono inexplicable, en término de Villamol.
} 
Alonso Zamora Vicente (1999: 64) escribe sobre nuestro hombre:

Desempeñó el curato de Santiago en Talavera de la Reina y lo mismo en Albares, lugar alcarreño (1680), junto a Mondéjar, donde manejó la rica biblioteca de los marqueses de ese título y trató personalmente a los dueños, y de allí pasó a Camarma de Esteruelas (1685), junto a Alcalá de Henares, donde estableció contacto con esta universidad.

Un contacto dilatado y fructífero pues, según anota Francisco Martínez (1982: 223), en ella es "alumno primero y profesor después durante doce años".

A la Corte llega, de la mano del cardenal Portocarrero, en los últimos años del siglo. Allí desempeñará el curato de San Pedro trasladándose posteriormente a la parroquia de San Andrés. Y en Madrid trascurrirá el resto de su vida, donde, desempeñará importantes cargos (Zamora, 1999: 64): “examinador de la Nunciatura, calificador del Santo Oficio, visitador de librerías, Primer Bibliotecario Mayor del Rey (a la fundación de la Biblioteca por Felipe V, en 1712)" y donde renunciará a otros aún mayores, entre ellos los obispados de Monópoli, Nápoles y, posteriormente, Zamora. La fama que precedía a Juan de Ferreras cuando muere, en 1735, con ochenta y tres años, debía ser bien notoria pues en el margen de su asiento de bautismo se anota en ese momento lo siguiente: "allose quando murió que fue el año de 1735, aver renunciado tres obispados, y llevó tres mitras a los pies".

Hombre polifacético, culto y preparado, sus escritos dan fe de su diversidad intelectual: escribió una historia de España, probablemente su mejor obra, compuesta de 16 tomos titulada Synopsis histórica chronológica de España, formada de los autores seguros y de buena fe. Y muchas otras obras, en su mayoría inéditas, algunas publicadas póstumamente, de carácter teológico, político o literario ${ }^{6}$.

\footnotetext{
${ }^{6}$ Algunas de estas obras dignas de mención son: De fide theologica: disputationes schcolasticae... (1692); Disputationes theologicae de Deo uno et trino primoque rerum omnium creatore (1735); Novena y compendio de la Vida de San Francisco de Sales, Obispo y Príncipe de Ginebra (1749); Dissertatio apologetica de praedicatione S. Apostoli Iacobi Zebedei in Hispania (1722). Sobre los manuscritos conservados de Ferreras ha de consultarse el texto de Gregorio de Andrés (1983).
} 
El papel de de Juan de Ferreras en la Real Academia debió de ser fundamental tanto en la fundación propiamente dicha como en su posterior desarrollo. Lo demuestra el hecho de que, cuando casi un año después de que se solicitase la protección real, el Rey firmó la cédula de creación de la Academia (dada en Madrid a tres de octubre de 1714), los académicos se reunieron para elegir nueva y formalmente los cargos de secretario y director. Squarzafigo y el marqués de Villena fueron confirmados, respectivamente, en los mismos a pesar de que este último propuso a Juan de Ferreras para director (Cotarelo, 1914: 37).

Por lo demás, Juan de Ferreras, a cuya intervención se atribuye la costumbre de iniciar y finalizar las reuniones con el rezo de una antífona7, se encuentra entre los miembros de la Academia a los que Fernando Lázaro Carreter (1981: 114) califica de "muy diligentes" por el extraordinario grado de cumplimiento de que hacen gala en las tareas que se les encomiendan para la formación del Diccionario de Autoridades cuyo primer tomo aparecerá, después de avatares incontables, en 1726:

En dos años y medio acaban su tarea Ferreras, Saldueña, Squarzafigo, Casani, Barcia, Alcázar, Connink, Villademoros, Dongo Villena y Ayala. Estos mismos redactores han terminado su primer tratamiento de la $B$, en mayo de 1716 .

Zamora Vicente (1999: 64) también alude al ingente y presto trabajo de Ferreras en la Academia:

Colaboró en el Diccionario con seriedad y eficacia. Aparte de algunas combinaciones de A, elaboró la letra G, ya aprobada en 1731. En esa fecha Ferreras anda ya por los setenta y nueve años: no es de extrañar que su colaboración desaparezca. Sin embargo, Nassarre nos dice que Ferreras llegó a "nuestros días con una sanidad capaz de sufrir las inmensas fatigas del ministerio y las del continuo estudio". Con Ferreras se inició la costumbre, incluida posteriormente en el Reglamento (1861) de considerar presente en todas las juntas al académico que reúna ciertas condiciones.

\footnotetext{
7 Cotarelo Mori (1914: 38) data esta costumbre con precisión. Tiene lugar por vez primera el día 28 de octubre de 1714: "Juan de Ferreras recitó al principio Veni, Sancte Spiritus y la oración Actiones nostras quaesumus, Domine...y terminó con Agimus tibi gratias según propuso el director".
} 
Ferreras, que ocupó el sillón B (hasta el año 1847, cuando la reina Isabel II aprueba aumentar el número de académicos hasta treinta y seis, no habrá sillones de letras minúsculas), murió el 8 de junio de 1735. De él conservamos un interesante retrato, guardado en la Biblioteca Nacional, que nos le muestra con ojos grandes y vivos, la nariz prominente, el cuello corto, los labios bien marcados, la calvicie avanzada y un gesto que apunta una sonrisa velada.

\section{Alonso Rodríguez Castañón}

La Real Academia pierde muy pronto a uno de sus miembros: el sevillano Gabriel Álvarez de Toledo. Muere en Madrid en el mes de enero de 1714: “Ni siquiera alcanzó a vivir el momento de la consagración oficial del proyecto de Villena", recuerda Zamora Vicente (1999: 66). En efecto, la cédula real que daba vida "oficial" a la Academia no llegaría hasta el mes de octubre de ese mismo año. Aun así, su labor no debe ser echada en el olvido puesto que, como anota Francisco Martínez (1982: 224), su papel en la elaboración de los estatutos de la Academia, precisamente junto a Juan de Ferreras, fue de importancia.

El sillón C que ocupara Gabriel Álvarez de Toledo, bibliotecario del Rey, oficial de la Secretaría de Estado, escritor (sus obras se publicaron póstumamente gracias a Torres Villarroel) y humanista en toda regla, quedó largamente vacante. Exactamente hasta 17178 , cuando es elegido para el mismo Alonso Rodríguez Castañón. Este es el párrafo que Alonso Zamora Vicente (1999: 66) le reserva:

Le sucedió Alonso Rodríguez Castañón, también caballero de Alcántara, y Colegial del Mayor de San Ildefonso, de Alcalá de Henares. Al parecer fue visitante de la Academia en 1717 (11 de

\footnotetext{
8 Si no hay duda de que su incorporación se produce ese año (no el de 1714, como erróneamente consta en muchas relaciones de académicos e incluso en la página web de la RAE), varía la fecha exacta en que se realiza. Alonso Zamora Vicente (1999:28) apunta que "no se cubrió su hueco hasta mayo de 1717" mientras que Lázaro Carreter (1981:98) alude a esta sustitución el 1-IV-1717. El texto de Cotarelo Mori (1914:105), es coincidente son el de este último pues indica que su toma de posesión como académico se habría producido en 1 de abril de ese año (tras votarse su ingreso el día 18 de marzo).
} 
febrero); volvió, picada su curiosidad, en 4 de marzo. El día 17 envió su memorial solicitando ser admitido. No colaboró apenas, seguramente por su traslado a Sevilla, como fiscal de la Audiencia. Murió en esta ciudad, el 16 de junio de 1725.

Emilio Cotarelo Mori (1914: 105) es algo más explícito sobre nuestro personaje: Con más reposo que Scotti tomó el negocio de su entrada en la Academia D. Alonso Castañón, caballero de Alcántara y colegial mayor de San Ildefonso en la Universidad de Alcalá. Pidió permiso, como forastero, en 11 de febrero de 1717, para asistir a una junta y, concedido, ocupó el lugar inmediato a Ferreras. Volvió con el mismo carácter el 4 de marzo y, por fin, el 17 envió su memorial, se leyó y votó el 18 en reemplazo de D. Gabriel Álvarez de Toledo, fallecido, como hemos dicho, en 1714 . El $1^{\circ}$ de abril se presentó a tomar posesión diciendo de voz y entregando escrito su discurso en elogio de su antecesor. Asistió, aunque con poca frecuencia, hasta abril de 1719, y en $1^{\circ}$ de agosto del año siguiente se le escribió recordándole sus deberes, y que, no obstante su asistencia por temporadas a la Corte, no iba a la Academia. Disculpose con una molesta enfermedad de cuartana que le forzó a retirarse a la Montaña, su patria, para reponerse y que, vuelto a su Colegio de Alcalá, estaba dispuesto a trabajar en lo que pudiese en servicio de la Academia. Admitiósele la buena voluntad, porque no consta que hubiese hecho cosa alguna. Nombrado fiscal de la Audiencia de Sevilla, allí falleció el 6 de junio de 1726.

Nada se nos dice de sus orígenes o su lugar de nacimiento. Presupongo que tal dato no le consta a ninguno de los autores consultados, pues es uno de los que sí suelen aportar. Pues bien, Alonso Rodríguez Castañón nació en el lugar de Lois9 provincia de León, y fue bautizado el 7 de octubre de 1669. Su partida de bautismo10, que he visto, reza así:

En siete de octubre de mill y seiscientos y sesenta y nuebe años Bapticé in facie eclesie a Alonso hijo de Diego Rodríguez y María de Balbuena su muger vecinos deste lugar fueron sus Padrinos Pedro de Valbuena vecino de Salamón y Catalina Gutiérrez muger de Pedro Rodríguez y Por verdad lo firmo ut supra. Diego Álvarez Azebedo y Reyero.

\footnotetext{
9 Aunque también desconoce Cotarelo el lugar del que es oriundo Alonso Rodríguez Castañón, indirectamente confirma nuestra investigación con esa interesante alusión a que su patria era "la Montaña".

${ }^{10}$ Libro de Bautizados de la Parroquia de Lois, 1603-1688.
} 
Pertenecía Alonso Rodríguez a una linajuda familia del lugar de Lois, la de los Rodríguez Castañón, una de las varias que a partir de siglo XVI tuvieron una preeminencia clara y fehacientemente documentada en Lois. Los Castañón, según se desprende de los estudios inéditos del erudito leonés D. Salvador Alonso, tenían sus orígenes en Asturias, y más concretamente en Nembra, concejo de Aller, y sus miembros habían ostentado relevantes cargos en los ámbitos civil y eclesiástico: dos de ellos, Juan Antonio y Antonio, habían sido obispos, respectivamente, de Zamora y Ciudad Rodrigo; otro, Alonso, general de Artillería y, finalmente, Diego, comisario general de Vizcaya.

Tras asentarse en Lois y emparentar con los Rodríguez, en la familia se crearán al menos dos mayorazgos, pues al principal o inicial establecido por Juan Rodríguez Castañón ${ }^{11}$ se sumó el instituido por uno de sus hijos, Domingo, rector de Quintanilla, a favor de su hermano Pedro. En Lois la familia continuará haciendo gala de miembros ilustres quienes -y esto es ciertamente lo importante- ponen su influencia y su poder económico al servicio de sus convecinos. Así, a Francisco Rodríguez Castañón (Lois, 1614-Calahorra, 1669), obispo de Orense y electo de Calahorra, se debe el primer intento serio de erigir una iglesia de nueva planta en Lois $^{12}$ que, como es sabido, culminará otro miembro de la familia: Juan Manuel Rodríguez Castañón (Lois, 1695- Tuy, 1769), obispo de Tuy (Pontevedra). Pedro Rodríguez Castañón ${ }^{13}$ (1665-1719?), penitenciario de Valladolid, fundó la escuela de

11 Este era, sin duda, el mayorazgo principal tal como se deduce de las palabras de Jerónimo Rodríguez Castañón quien en el Memorial de fundación de la cátedra de latín que establece en Lois se refiere a esta línea como la "originaria patronímica y primitiva de los Rodríguez de Lois". El mayorazgo instituido por su hijo Domingo se extinguió tras la muerte de D. Juan Manuel Rodríguez Castañón, obispo de Tuy, volviendo sus bienes al tronco principal con excepción de la casa que, desvinculada, se ofreció al presbítero encargado de la capellanía del Pilar fundada en la iglesia.

12 Por sus dimensiones y características arquitectónicas, la iglesia de Lois, construida íntegramente con sillares de jaspe rosado, ha recibido el apelativo de "la catedral de la montaña".

${ }^{13}$ Es hermano de Alonso Rodríguez Castañón quien será, tras la muerte de aquel, el encargado de hacer realidad y poner en marcha las dos obras instituidas. La escuela era gratuita, tanto en la enseñanza como en los materiales. 
primeras letras de Lois y dotó una beca para un estudiante de su familia. Jerónimo Rodríguez Castañón (Lois, 1695-Toledo, 1742), colegial en el San Ildefonso de Alcalá y capellán de Reyes Nuevos de Toledo, fundará una ejemplar cátedra de latín ${ }^{14}$, tradicionalmente conocida como "la universidad de la montaña", de excepcional importancia para la preparación cultural de los habitantes de Lois y su entorno, inmediato y no tan inmediato, cuya vida se extenderá hasta los años sesenta del siglo XX. Finalmente, hay que hacer mención de María Rodríguez Castañón, hermana del anterior, que, profesa en el monasterio benedictino de Otero de las Dueñas (León), desaparecido tras la Desamortización, fue su abadesa.

Ninguna otra familia del lugar tuvo mayor generosidad que la de los Rodríguez Castañón con la tierra que les vio nacer pero que pronto abandonaron: la escuela, la cátedra, la beca de estudiantes y la iglesia y sus alhajas han sido durante varios siglos, y aún son, la prueba de una productiva vinculación voluntariosa, estrecha y filantrópica.

Alonso Rodríguez Castañón pertenecía al tronco principal de los Castañones de Lois: era nieto del fundador del mayorazgo, Juan Rodríguez Castañón, que había heredado su padre, Diego, y heredaría después su hermano Carlos. Habitaban en una casa que desde su construcción por parte del abuelo se había conocido en el lugar como Grande o Palacio, pues con ese nombre aparece mencionada en diferentes documentos notariales del siglo XVIII. De ella nada queda en la actualidad, salvo el nombre, pues fue reconstruida íntegramente. En el último cuarto del siglo XIX el edificio se hallaba completamente arruinado. En ese lamentable estado lo conoció el canónigo natural de Crémenes José González cuando, siendo un niño, llegó a Lois para echar los latines en su famosa cátedra. Años después, en uno de sus muchos escritos con los que trataba de divulgar los encantos y la importancia cultural del lugar, recordaría a propósito de esta casa cómo "los paredones de piedra

\footnotetext{
14 Para los datos sobre esta fundación de gramática, puede consultarse la obra de las profesoras Cantón y Prieto (1997).
} 
de sillería, algunas ventanas, jambas, cerraban un recinto de escombros donde crecían el jaramago y las ortigas".

La construcción actual, de finales del XIX, nada tiene que ver con la primigenia aunque en ella se han empleado elementos de la original, algunos de los cuales pueden verse empotrados en la fachada. De aquélla, que delante tenía un hórreo, conservamos una descripción de 1775 inserta en el inventario de bienes de Francisco Rodríguez Castañón conservado entre los protocolos notariales, sin relacionar ni clasificar, que se guardan en el Ayuntamiento de Crémenes:

La casa principal de sillería con tres balconadas de yerro, cubierta de paja, con tres escudos de armas, dos de piedra y otro de yerro propios y pertenecientes del apellido de Rodríguez Castañón y se compone lo principal de dicha casa de anteportal, portal y bodega por lo bajo y un cuarto separado a la mano izquierda y sigue con escalera de piedra y barandillas de yerro con seis bolas de bronce, cocina en el segundo piso, sala y una alcoba para dormitorio y en el tercero y último piso otra sala y alcoba dormitorio y sobrecocina...

El estatus familiar permitió que Alonso Rodríguez Castañón abandonase pronto su lugar de origen para comenzar una larga y productiva formación que culminaría con su nombramiento como fiscal de la Audiencia de Sevilla. Diversos documentos oficiales ${ }^{15}$ nos permiten conocer íntegramente su vida académica y profesional: varias relaciones de méritos, expedientes de la Universidad de Alcalá, el expediente formado cuando toma el hábito de Alcántara. Sin embargo carecemos totalmente de datos de tipo personal e ignoramos, incluso, quién heredó sus bienes y si estos revirtieron en el mayorazgo familiar.

Sus primeros estudios le sitúan, con apenas 15 años, en la Universidad de Oviedo donde cursa Súmulas, Lógica y Filosofía (1684, 1685 y 1686). De allí debió trasladarse a la Universidad de Valladolid, en la que alcanza el grado de Bachiller en Leyes en veintiocho de mayo de 1692, y después a la de Salamanca, pues en 17 de febrero del año siguiente obtiene el de Bachiller en Cánones, “incorporándose en

\footnotetext{
${ }^{15}$ Los datos están extraídos de varias relaciones de méritos correspondientes a los años 1703 [AGI, Indiferente, 136. no 190], 1704 [AGI, Indiferente, 136. nº 190] y 1715 [AGI, Indiferente, 139, nº 34]
} 
Leyes", refieren los documentos, en 15 de enero de 1695. En ese mismo año, concretamente en 15 de diciembre, comienza a ser opositor a la cátedra de Vísperas de Leyes y simultanea “explicar extraordinario” durante los cursos 1694/95/96.

Elegido colegial mayor, jurista, en el Colegio San Ildefonso de la Universidad de Alcalá16 en 11 de agosto de 1697 ("y para ello consta haber leído una hora de arena", anotan los documentos), se licencia en Cánones por la Universidad de Ávila en trece de noviembre de ese mismo año, incorporando el grado en la Universidad de Alcalá pocos días después. Parece oportuno recordar que el Colegio San Ildefonso de Alcalá, del que será colegial Alonso Rodríguez Castañón al igual que su hermano Pedro y después sus parientes Jerónimo Rodríguez Castañón y Juan Manuel Rodríguez Castañón, había sido una fundación del cardenal Cisneros y se componía de 33 colegiales y 12 capellanes.

En Alcalá de Henares se desarrollará el resto de su vida académica17: sustituye "pro Universitate" la cátedra más antigua de Instituta (1699), profesor en la cátedra de Instituta (1700), sustituye varias veces la cátedra de Decretales Mayores (1701) y sustituye muchos días la cátedra de Decretales Menores en 1702. Visitador por nombramiento de la Capilla del Sr. Rector en 1702 y 1703, sustituye "pro Universitate" la cátedra de Sexto en 1703, año en que toma el hábito de la Orden de

\footnotetext{
16 Para todo lo relacionado con la Universidad de Alcalá y el Colegio Mayor de San Ildefonso resulta imprescindible la obra de Gutiérrez Torrecilla y Ballesteros Torres (1998). Con documentos del AHN, sección Universidades, los autores elaboran la ficha personal de Alfonso (sic) Rodríguez Castañón. Resulta sorprendente que, al contrario de lo que ocurre con otros catedráticos universitarios, en este caso no se haga referencia ni a su destino final ni a los cargos desempeñados.

${ }^{17}$ Las cátedras de la Facultad de Derecho Canónico de la Universidad de Alcalá eran todas de regencia (no en propiedad) y el orden de su desempeño, de mayor a menor importancia, era: Prima de Cánones, Vísperas de Cánones, Decreto, Sexto, Decretales Mayores, Decretales Menores, Instituta II e Instituta I. Las dos últimas, introducidas en la segunda mitad del XVII, eran de derecho civil, en realidad derecho romano. Sustituir "pro Universitate" una cátedra consistía en cubrir una vacante, con carácter interino, por encargo de la propia universidad.
} 
Alcántara ${ }^{18}$. Un año después (1704), es beneficiado de la parroquia de San Miguel de Villanueva del Condado, diócesis de León, señorío de los duques de Medinaceli.

Toma posesión de la cátedra de Instituta de libro primero el 16 de agosto de 1708 y de la cátedra de Instituta de libro segundo el 4 de abril de 1713 accediendo a la de Decretales Menores el 28 de septiembre de 1714. Se encuentra precisamente desempeñando esa cátedra, que compagina con el cargo de visitador de la Orden de Alcántara para la Serena y su partido, cuando se produce su contacto y su ingreso en la Real Academia en la que ocupa el sillón C.

Obtiene la cátedra de Decreto el 5 de noviembre de 1718 y parece que es entonces cuando renuncia al nombramiento de fiscal para la Fiscalía de Lima, Real Consejo de Indias. Su vida sigue ligada a la Universidad de Alcalá donde el 7 de julio de 1722 toma posesión de la cátedra de Vísperas. Solamente permanecerá en ella dos años, pues en 1724 es nombrado fiscal de la Audiencia de Sevilla. Muere en Sevilla el 6 de junio de 1725 ignorándose la iglesia en la sus restos recibieron sepultura. No ha sido posible tampoco encontrar su testamento, a pesar de que sabemos de manera indirecta no solamente que lo otorgó en Alcalá de Henares sino incluso la fecha en que lo hizo.

De su paso por la Academia no tenemos muchos datos pero colegimos de las palabras anteriormente citadas de Cotarelo que su papel en ella fue absolutamente irrelevante. Debió de ausentarse frecuentemente pues Lázaro Carreter (1981: 116) recoge en su estudio que Manuel de Fuentes fue expulsado de la Academia en 1717 por incomparecencia manifiesta (no volvió desde su recepción), algo que se repetiría años después, en 1720 (acta de 17 de agosto), con Solís, “que llevaba cuatro años sin comparecer". En la misma sesión en que se toma esta decisión, "se exhortó a Castañón para que se explicara, pero le sirvieron de disculpa unas cuartanas". Zamora Vicente precisa la situación explicando que fue en la siguiente sesión cuando

\footnotetext{
${ }^{18}$ El expediente se encuentra en el AHN OM-Expedientillos N, 14419 y OM-Caballeros_Alcántara, exp. 1291.]
} 
Alonso Castañón se justificó "por haber pasado unas tercianas peligrosas" (Zamora: 1994: 106).

Lo cierto es que Alonso Rodríguez Castañón no residía en Madrid y que su alejamiento de la Academia es definitivo a raíz de su nombramiento en 1724 como fiscal de la Audiencia de Sevilla. Hay, sin embargo, un hecho que lo convierte en personaje de cita ineludible para la historia de la Real Casa. Nos lo proporciona nuevamente Lázaro Carreter (1981: 98) al anotar: “El ritual elogio del académico fallecido por quien ocupa su plaza, lo instauró Alonso R. Castañón al sustituir a Álvarez de Toledo". El mismo dato puede encontrarse en Zamora Vicente (1994: 28): “Con su discurso de entrada, nació la costumbre, mantenida vigente hasta hoy, de que el nuevo académico pronuncie el elogio de su precedesor en la silla".

\section{Pedro Manuel de Acevedo}

La expulsión de Jaime Solís de la Academia a la que se ha aludido poco ha, dejó vacante el sillón T. De nuevo es Zamora Vicente (1999: 90) quien hace luz en la sucesión:

Para llenar el forzado hueco de Solís la Academia eligió a Pedro Manuel de Acevedo, hijo de un Consejero de Castilla, Baltasar de Acevedo, en febrero de 1721. Acevedo, caballero de Santiago, regidor perpetuo de Soria, sargento mayor de la Caballería, gobernador de Jerez de los Caballeros y finalmente regidor en Daroca, recibió varios encargos para el Diccionario; sobre todo las tareas que no acabó Bacallar y Sanna y las del excluido Solís. Papeletizó las Leyes de la Mesta. Acevedo, que había luchado en la guerra de Sucesión a favor del bando borbónico, murió en Daroca el 16 de febrero de 1734. Molins dice que "de un accidente repentino".

Tampoco debe constarle al autor en este caso el origen del académico, al que no alude, y que, para sorpresa inaudita, no es otro que la provincia de León. Y, más concretamente, el lugar de... Lois.

Pedro Manuel de Acevedo había nacido, no obstante, en Madrid el 20 de diciembre de 1684 y fue bautizado en la iglesia parroquial de Santa Cruz unos días después: el 29 de diciembre. La parroquia se hallaba entonces en la plaza de su 
nombre, pues no sería hasta la década de los setenta del siglo XIX cuando se trasladase a la que es su ubicación actual en la calle de Atocha, en el solar que había sido anteriormente convento dominico de Santo Tomás.

Resulta curioso constatar que este hombre, como su padre en muchas ocasiones y algunos otros miembros de su familia, omite el primer apellido que lleva: Álvarez. No cabe, sin embargo, sospechar nada extraño. De hecho el propio Alonso Rodríguez Castañón lo hace a menudo, siendo más conocido por su segundo apellido que por el primero. Probablemente tenga también que ver con el hecho de que la vinculación a sus respectivos mayorazgos viniese ligada, respectivamente, a los apellidos Castañón y Acevedo.

Pedro Manuel de Acevedo era hijo de Baltasar Álvarez de Acevedo (16551722), notorio e importante abogado de los Reales Consejos y natural de Lois ${ }^{19}$, y de Isabel Volante, natural de Madrid pero descendiente por línea paterna de la villa de Almanza (León).

Los Álvarez Acevedo fueron, en efecto, una familia de hidalgos cuyos miembros alcanzaron a lo largo de su historia importantes puestos en el entramado civil, militar y eclesiástico del Reino. El mayorazgo fundado en el siglo XVI por Diego Álvarez y Catalina Álvarez Acevedo, constructores de la casa familiar, entroncó inmediatamente por vía de matrimonio con los Ordás, cuyo espléndido palacio en la población de Otero de Curueño (León) permanece aún en pie. Desde entonces y hasta el siglo XX, muchos fueron los Álvarez Acevedo de renombre en el país: Juan Álvarez ${ }^{20}$, obispo de Oviedo; Antonio A. Acevedo (Lois, 1646-

\footnotetext{
${ }_{19}$ Desempeñó, entre otros, los cargos siguientes: abogado de los Reales Consejos y fiscal del Real Bolsillo y Gastos Secretos de S. M.; abogado general en el Real Consejo de Indias (1713); cuarto presidente en el Real Consejo de Hacienda (1714); fiscal de la Sala de Millones en el Real Consejo de Hacienda (1715); ministro de la Sala de Justicia, en el Real Consejo de Hacienda (1717); consejero real en el Consejo Real de Castilla (1720).

${ }^{20}$ Juan Álvarez era tío abuelo de Baltasar Álvarez Acevedo, padre del Pedro M. Acevedo; Antonio, obispo de la Orden de Santiago, era su hermano.
} 
Llerena,1711), prior de San Marcos de León y obispo de la orden de Santiago; Tomás Álvarez Acevedo21, fiscal de la Audiencia de Lima y regidor de Chile; Félix Álvarez Acevedo, coronel proclamado por el Parlamento Benemérito de la Patria...y, por supuesto, D. Mariano Álvarez Acevedo (Otero de Curueño, 1807-Madrid, 1872), el infatigable diputado liberal en Cortes que fue capaz de ensayar famosas inversiones en la montaña leonesa.

Los Álvarez Acevedo disponían, como es natural, también de casa solariega en el lugar de Lois, donde puede contemplarse aún hoy. Es, precisamente, una de las que mejor conservan las trazas de lo que debió ser en tiempos. La edificación ocupa notables dimensiones y conserva parte de un muro de mampuesto, que muy probablemente circundó originariamente toda la propiedad, en el que aún se aprecian dos cubos y bellos dinteles labrados que debieron enmarcar el acceso principal. Construida en dos alturas, la casona tiene una elegante fachada de sillares calizos rosados en la que destacan unas grandes puertas de acceso al edificio y los dos balcones con rejería de la parte superior. Y aunque en la casa no se conserva escudo de armas alguno, sabemos que lo tuvo e incluso su emplazamiento gracias a un documento del año 1705 con el que se probaba la limpieza de sangre del ya citado Tomás Álvarez Acevedo. El notario Lorenzo Gómez de Caso anota, entre otras cosas:

He visto de ojos la casa y armas del linaje de Acebedo de Lois y la casa tiene cuatro frentes y está en la parte alta del pueblo. Un frente cae encima del río y es todo de piedra de sillería. Del cual se forman dos ramas de muralla con un cubo con troneras y almenas y la puerta es de arco de medio punto sobre el cual hay un escudo de armas, de relieve, formado de cuatro cuarteles; el primero que es de los Álvarez tiene un castillo con tres calderas; encima, flores de lis, y al pie, orlado, doce roeles. El segundo tiene un roble con dos lobos que pertenecen a los Acevedos. En los cuarteles inferiores hay, en cada uno, un castillo con cinco flores de lis. De

\footnotetext{
${ }^{21}$ Tomás Álvarez Acevedo es, sin duda, la figura que destaca políticamente en la familia. Nacido en Lois en 1735, desempeñó los siguientes cargos: fiscal de la Audiencia de Charcas, en el Virreinato del Perú (1766); gobernador de la villa de Potosí (1776); fiscal de la Audiencia de Lima y regente de la Real Audiencia de Chile (1776); capitán general interino y presidente de la Real Audiencia de Chile 1780); caballero de la Muy Real y Distinguida Orden de Carlos III (1786); regente nuevamente de la Audiencia de Chile (1787-1788) y consejero de la Real y Supremo Consejo de Indias (1788).
} 
todo lo cual se comprende que es una familia de las principales del país, calificada de caballeros e hidalgos. Lo firmo en Lois a diez de agosto.

Pero si Alonso Rodríguez Castañón pasó por la Academia sin pena ni gloria y en el trabajo del Diccionario de Autoridades no invirtió tiempo ni esfuerzo, no puede decirse lo mismo de Pedro M. Acevedo. Antes bien, todo lo contrario. Aparte del dato proporcionado por Zamora Vicente de que papeletizó las Leyes de la Mesta (¿casualidad o conocimiento? El lugar de Lois es famoso por sus puertos de altura, destino secular, y aun actual, de las ovejas trashumantes; muchos de sus habitantes han sido pastores; en el lugar había ropería...y un largo etcétera), Acevedo recibe en la sesión de 10 de enero de 1724 el encargo de $\mathbf{B}$ ante $\mathbf{E}$ y acaba el trabajo en 8 meses. Algo increíble si se tiene en cuenta que el primer destinatario del trabajo había sido Mercurio Fernández Pacheco, hijo del fundador, que en 1717, tras tres años sin hacer nada, se declara incapaz. Pasa el encargo a Villademoros que emplea otros tres años pero lo hace sin llegar a entregarlo: cuando muere en 1723 el trabajo no se halla por parte alguna...

No será el único remiendo que acometa Pedro M. de Acevedo: corrige $\mathbf{C}$ ante A, trabajo realizado por Barcia de forma totalmente asistemática $\mathrm{y}$, por lo tanto, inservible; y "cargará" (cito textualmente a Lázaro Carreter por la expresividad que imprime al verbo) con la combinación AU que en la que no había nadie trabajando. Gracias a su perspicacia (Acevedo plantea a los académicos si ha de separar las voces en que $u$ es semivocal o semiconsonante), la docta casa (Lázaro, 1981: 120) "adopta otra importante decisión: la ya anunciada de distinguir, definitivamente, la $v$ de la $u^{\prime \prime}$.

\section{Casimiro Flórez Canseco}

No se había cumplido aún el primer siglo de vida de la Academia cuando en ella entró otro leonés, el cuarto: Casimiro Flórez Canseco.

Si Pedro M. Acevedo había sido militar de profesión, un intelectual rotundo tomaba el testigo. Le damos la palabra de nuevo a Zamora Vicente (1994: 188): 
Desde 1802, está la silla P en poder de Casimiro Flórez Canseco, abogado del Colegio de Madrid, catedrático de griego y secretario de los Reales Estudios de San Isidro. Y no podemos decir mucho más: lo señalado es lo que nos proclaman los preliminares del Diccionario de 1803. Flórez Canseco fue honorario en 1792, y de número a la muerte de Ignacio Hermosilla, 1802. Nos le suponemos sumergido en sus antiguos textos y viendo con asombro los acaeceres de la invasión francesa, y más tarde, los perpetuos sobresaltos políticos al regreso de Fernando VII. Por fuentes laterales a la Academia sabemos que publicó su traducción de la Poética de Aristóteles (1778) y el Sueño de Luciano, en el mismo año. En 1781, apareció su versión de Jenofonte (3 volúmenes, en la Imprenta Real) y dejó inédito un Método para enseñar y aprender la lengua griega. Había desempeñado la cátedra de griego en Salamanca y, en ocasiones, utilizaba el seudónimo de Antheo Manterano. Canseco, nacido en León, en 1745, murió en Madrid el 3 de mayo de 1816.

No es poco, pese a la humildad de que hace gala el autor, lo aportado sobre Casimiro Flórez Canseco. Pero de él disponemos de muchos otros datos. Nació en 1745 en la provincia de León, en concreto en el pueblo de Manzaneda de Torío, hijo de Francisco Flórez y Ángela Canseco, que habían contraído matrimonio el 1 de octubre de 1738. Y es poco o nada más lo que sabemos de sus primeros años, a no ser que interese a alguien su fecha de confirmación, recibida en Robles el 13 de junio de 1749, y el dato importante (Menéndez, 1962: 67) de que estudió latín en la preceptoría de San Feliz de Torío (León), fundación que había echado andar en 1747. Después completó su formación en la Universidad de Salamanca, donde cursó Filosofía y Leyes a la sombra de Alonso Canseco de Robles, tío suyo y catedrático de la misma, primero de Súmulas y luego de Álgebra. A partir de ahí, es la investigadora Concepción Hernando (1975: 80) quien en un magnífico trabajo recoge el discurrir profesional de un hombre al que no duda en calificar "una de las figuras más destacadas de nuestros helenistas del siglo XVIII".

Su expediente como opositor en 1771 a la cátedra de griego de los Reales Estudios de San Isidro nos informa de que era bachiller en Cánones y Leyes por la Universidad de Salamanca y había cursado tres años de artes; que había asistido tres años a la cátedra de Lengua Griega y otros tres a la celda del Padre Bernardo de Zamora, que era catedrático de Griego en esa universidad; y que en junio de 1770 fue abogado de los Reales Consejos. Desde 1771 su vida se vincula enteramente a la 
enseñanza en los Reales Estudios de San Isidro donde será primeramente pasante (1771-1777) y posteriormente catedrático griego (1778-1815).

La intensa y total vinculación de Flórez Canseco a los Reales Estudios de San Isidro de Madrid obliga a hacer una referencia, aunque sucinta, a éstos. Sus orígenes se remontan al colegio jesuítico de San Pedro y San Pablo que el conde de Feria decide fundar en 1558, a instancias del Padre Rivadeneyra, en Madrid. Inicialmente se pensó ubicarlo junto a la puerta de Balnadú, en un terreno comprado para tal efecto, pero Felipe II paralizó el proyecto porque esos terrenos afectaban a la prolongación del Alcázar. Por esa razón, el edificio no se hizo realidad hasta 1564 cuando se construyó en la calle Toledo, en unos terrenos cedidos por doña Leonor de Mascareñas, dama de la emperatriz Isabel. San Francisco de Borja ordenó en 1572 ponerlo en marcha enseñándose en él gramática, retórica y teología.

El colegio mantuvo una excepcional relación con la emperatriz María de Austria, hija de Carlos V quien, tras enviudar de Maximiliano, regresó a Madrid para ingresar en el Monasterio de las Descalzas Reales. En su testamento dejó importantes fondos para edificar de nueva planta el colegio y así fue como tras su muerte, acaecida en 1603, el colegio se volvió a fundar con el nombre de Colegio Imperial edificándose el nuevo edificio - el actual Instituto de San Isidro- con trazas de los arquitectos Francisco Bautista y Melchor de Bueras entre los años 1622 y 1644.

Propiamente hablando, el fundador de los Reales Estudios de San Isidro cuyos estatutos se redactaron en 1625- fue el rey Felipe IV, que concentró en ellos las enseñanzas de otras instituciones anteriores tales como el Estudio de la Villa o la Academia de Matemáticas. Y el colegio logró reunir una excepcional biblioteca, considerada la más importante biblioteca de Madrid hasta el siglo XVIII, cuyos fondos (hoy repartidos entre la Universidad Complutense y la Real Academia de la Historia) provenían, entre otros, de legados de benefactores y documentos de los jesuitas allí reunidos.

Desde su fundación hasta su desaparición, la docencia se impartió ininterrumpidamente con una excepción: los años que mediaron entre 1767, fecha de 
la expulsión de los jesuitas, y el año 1770 en que Carlos III refundó los Reales Estudios (firmó el decreto del restablecimiento de los Reales Estudios el 19 de enero de 1770 y la ceremonia de inauguración de los mismos tuvo lugar el 21 de octubre de 1771) encargando las cátedras a maestros nombrados por el Rey. El primer director de este periodo fue Felipe Samaniego y el segundo Manuel Villafañe, que protagonizará con Casimiro Flórez Canseco un espinoso asunto.

Los jesuitas volvieron a encargarse de la enseñanza entre 1816 -año de la muerte de Flórez Canseco- y 1820 y, de nuevo, tras el trienio liberal, entre 1823 y 1834, fecha en la que son expulsados de nuevo. En 1835 los Reales Estudios se convierten en una institución laica, denominada Estudios Nacionales, y diez años después en el actual Instituto San Isidro.

La vida profesional de Casimiro Flórez Canseco se incardina en los Reales Estudios precisamente en el momento de la refundación de los mismos por parte de Carlos III. De hecho, nuestro personaje concurrirá a las primeras oposiciones a la cátedra de lengua griega que se convocan en febrero de 1770 (el tribunal será nombrado el 26 de septiembre de ese año) y que se desarrollarán en enero de 1771. Hernando (1975: 68) precisa los cinco ejercicios de que constaba la oposición: un tema teórico sobre morfología, sintaxis o fonética elegido entre tres sorteados; traducción directa de Tucídides; traducción directa de Homero; traducción de las Actas de los Apóstoles; traducción inversa de Cornelio Nepote. Por el expediente de la oposición sabemos, incluso, qué fragmentos de cada autor le salieron para traducir y el tema teórico que expuso: De graecorum accentibus, eorumque usu ac pronuntiatione et de graecorum spiritibus [Los acentos del griego -uso y pronunciación-. Los espíritus].

El tribunal de la oposición le otorgó la cátedra a Juan Domingo Cativiela nombrando a Casimiro Flórez Canseco pasante de la misma. Al catedrático, que tenía un sueldo de 1000 ducados, correspondía la sintaxis y la traducción en lengua griega mientras que al pasante, cuyo sueldo era exactamente la mitad, se le encomendaban los "rudimentos" de la lengua: grosso modo, el alfabeto, la lectura y la morfología al completo. 
Las relaciones entre catedrático y pasante nunca debieron de ser ni fluidas ni cordiales. No compartían siquiera la forma de pronunciar la lengua griega (la forma moderna el primero, la antigua el segundo) y Cativiela se quejaba de que Flórez se excedía al traducir el Nuevo Testamento cuando ésta era una atribución que no le correspondía a un pasante. Durante el curso 1771/72 se produjo entre ellos un desagradable episodio del que se hacen eco Luis Gil (1975: 68) y Concepción Hernando (1975: 405-418), quien nos proporciona una serie de documentos fundamentales para comprender en qué consistió lo que denomina el debate o la polémica de las gramáticas. Se trata de un enfrentamiento en el que participaron Cativiela, por una parte, y Flórez Canseco y Manuel Villafañe, director de los Estudios, por otra. El enfrentamiento se produce ante los alumnos cuando iba a comenzar el segundo trimestre y se iniciaba el estudio de la sintaxis. Manuel Villafañe y Casimiro Flórez Canseco querían adoptar como texto de la clase de griego la gramática del Fray Bernardo de Zamora ${ }^{22}$, catedrático de Salamanca desde 1764 y antiguo maestro de Flórez. El catedrático propietario, Cativiela, deseaba sin embargo explicar sobre la gramática del Seminario de Padua ${ }^{23}$ por considerarla la "mejor y ser notorio que es una de las más solemnes que circulan por el orbe literario". Creía, además que la gramática del P. Zamora "no debía admitirse para una perfecta enseñanza pública, no sólo por desconocida entre los literatos sino también por traer los preceptos gramaticales en unos versos durísimos y obscurísimos, estar falta de algunas reglas, manca y obscura en otras". Consecuentemente, recomendó, pues, el texto de Padua en enero de 1772 a sus alumnos.

Manuel Villafañe entró en el aula de Cativiela, amparándose en una resolución claustral favorable al P. Zamora, y le ordenó que "previniese a sus discípulos que, respecto de haber a mano copia de ejemplares de la citada gramática,

\footnotetext{
${ }^{22}$ Se trata de la Gramática Griega Filosófica, según el Sistema del Brocense, con las principales reglas en verso castellano: escrita por el M. Fr. Bernardo Agustín de Zamora, Carmelita Calzado, Lector en Teología, del Gremio y Claustro de la Universidad de Salamanca, su Cathedrático de Lengua Griega en propiedad. Madrid, en la Imprenta de Antonio Pérez de Soto, año de MDCCLXXI.

${ }^{23}$ Compendiaria Graecae Grammatices institutio in usum Seminarii Patavini.
} 
la comprasen luego". Cativiela se enfrentó al director diciendo "que no quería hacerlo, si el Rey no se lo mandaba, con otras expresiones muy impropias, y de tan perverso ejemplo para sus discípulos circundantes que dieron lugar a que uno de ellos perdiese el debido respeto al director". El enfrentamiento continuó durante casi dos años en los que Cativiela defendió con energía y tesón lo que hoy llamaríamos libertad de cátedra considerando que Manuel Villafañe se excedía en sus facultades de director, que no incluían "las de doctrina". Pidió incluso al Consejo que un grupo de expertos informasen sobre las distintas gramáticas, lo cual se hizo: la gramática considerada más adecuada no fue ninguna de las dos en disputa sino la de Francisco Vergara, catedrático de Alcalá en el siglo XVI, de la que no debía haber ejemplares pues el Consejo concede licencia para su reimpresión e, increíblemente, para que los propios Cativiela y su pasante "por vía de escolios, adición o advertencia añadan todo aquello que estimasen conveniente para la más fácil instrucción y claridad, así de ella como de la del Seminario de Padua, la del maestro Zamora y Pedro Simón Abril, a fin de que de este modo salga una obra completa para la enseñanza de esta lengua en los Reales Estudios..."

Tras la muerte de Juan Domingo Cativiela en 1777 se vuelve a convocar la cátedra de griego (Hernando, 1975: 266) de los Reales Estudios que al año siguiente, en 1778, gana Flórez Canseco quien, además, será secretario de la institución. En ella permanecerá hasta el año 1815. Tan larga permanencia dio como fruto que algunos de los mejores y más relevantes helenistas de la primera mitad del siglo XIX fuesen discípulos de Flórez Canseco. Es el caso de Acedo, Alejandro Albizú, Gómez Hermosilla (humanista, traductor en verso de la Ilíada de Homero y autor de una inconclusa e inédita Gramática Griega quien, además de alumno aventajado, fue pasante cuatro años con Flórez Canseco) y Saturnino Lozano que en el prólogo a la Gramática Griega que escribió se refiere a su maestro como "gloria de los Estudios Reales de esta Corte, llamados de San Isidro". Como curiosidad, es forzoso recordar que de este último helenista, incorporado a la Universidad Central tras su fundación en 1845, fue a su vez discípulo Lázaro Bardón y Gómez, extraordinaria figura bien conocida del helenismo leonés del XIX gracias, entre otros, a los estudios de los 
profesores (ambos filólogos clásicos) Santiago Olives Canals y el leonés Manuel Rabanal.

Otro de los aspectos a los que Casimiro Flórez se dedicó fue a la crítica literaria como censor. En Bordiga (2002: 215) podemos leer, incluso, su dictamen (que reprobaría sin duda la crítica actual) a propósito de la traducción de la obra de Voltaire Alcira, realizada por Margarita Hickey y Pellizoni ${ }^{24}$ y que no llegó a publicarse, de la que alaba la desfiguración realizada del original:

En Zayra y Alcira no puede negarse que hay en el original algunas proposiciones libres o mal sonantes; pero la traductora ha tenido al discreta y piadosa advertencia de omitir unas, rectificar otras y dilatar algún otro pensamiento en que los nimiamente cavilosos podían creer que el autor no se había explayado más por pura malicia y malignidad. Para evitar estos inconvenientes se ha visto precisada la traductora a apartarse alguna vez del original, y se ha extendido y añadido algo a los razonamientos de Nerestan y réplicas y reconvenciones de Fátima a Zayra, haciendo ver en ellos que sin el culto del verdadero Dios no puede haber verdadera virtud [...] Es además esta tragedia de las más patéticas, porque en ella todos los personajes son buenos, y representándosenos ahora exenta de los defectos del original, no puede dejar de producir su lectura y representación excelentes y provechosos efectos.

Por otra parte, en 1786 el Consejo le pide a Flórez Canseco su opinión sobre una obra que Pedro Estala pensaba publicar. Se trataba de las Odas de Anacreonte traducidas por Quevedo. Nuestro autor lo hace con minuciosidad tal (que le lleva a negar no solamente el valor de la traducción sino también la autoría de Quevedo de la versión) que Concepción Hernando (1975: 188), tras hacer hincapié en el rigor estético y la altura de que hace gala Canseco, concluye: "Nos hallamos ante un verdadero ilustrado, un genuino producto del neoclasicismo, que, a no dudarlo, de haberse desenvuelto en otros horizontes, hubiera producido frutos más fecundos".

La publicación de la obra de Estala se paralizó en ese momento aunque ocho años después finalmente se realizó. Conviene, sin embargo, dejar constancia de que este juicio negativo de la autoría quevediana (del que puede encontrarse noticia también en el Boletín de la Real Academia de 1949) no es compartido por todos los

${ }^{24}$ M. Hickey Pellizoni (Barcelona, 1753-1793), poetisa y traductora de obras de Racine y Voltaire. 
autores con el mismo entusiasmo: Enriqueta de Andrés Castellanos, por ejemplo, lo considera claramente un error.

Sabemos, en fin, que Casimiro Flórez Canseco animó la publicación de algunas otras obras en su tiempo. Nos consta por Sánchez Espinosa (2002: 271), por ejemplo, que tal ocurrió con la del ingeniero de minas irlandés Introducción a la historia natural y a la geografía física de España que se editó en Madrid en 1775 y se reeditó siete años más tarde. Así lo confirma una carta reproducida (sic) por G. Sánchez que el propio Bowles envió desde París a Daniel Sceideburg el 31 de mayo de 1774:

Je suis entierement toujours d'avis que mon ouvrage seroit plus honorable pour 1'Epagne si on le traduisoit en Castillane et l'imprimoit d'abord á Madrid. Mon ami Mr. l'avocat Florez etoit de la meme opinion, et je suis bien flatte que de celebres hommes, come Messieurs de Campomanes et Samaniego soient du meme sentiment. Mais Mr. de Florez est juge compentent, car il a lu un grand nome de mes dissertations qu'il pensoit dignes d'etre traduites en Espagnol. Je sais qu'il y a beaucoup d'Anglicismes et defauts dans mes phrases francoises qui seroient zero dans la traduction, et qui me coute bien des peines de faire corriger ici. N'importez pas je viens de donner dans les maines de S. E. Mr. le Comte d'Aranda ma dedicace au Rois d'Espagne et la Table des Matieres de tout l'ouvrage pour faire remettre par ale courier a S.E. Monsieur le Marquis de Grimaldi et la reponse decidera.

Casimiro Flórez Canseco no fue un autor prolífico. Todas sus obras publicadas o inéditas- están vinculadas de una u otra manera con la lengua griega y algunas, como se verá, tienen un interés notable, bien su contenido, bien por las circunstancias que en ellas concurrieron.

La primera de las obras que publicó fue El Sueño de Luciano Samosatense, que es la Vida de Luciano: Y la Tabla de Cebes, philosofo tebano en griego y español. Ilustradas con notas y la Análisis Gramatical para provecho de los que se aplican a la Lengua Griega, por el Lic. D. Casimiro Flórez Canseco. El volumen recogía dos obras, El sueño de Luciano, traducido por él mismo y La tabla de Cebes (Tabula Cebetis o Kebetos Pinax), en versión de Pedro Simón Abril. Se trata esta última de una ficción alegórica que muestra al hombre como peregrino en la tierra. Por su sencillez, brevedad (se publicaba por esa razón casi siempre conjuntamente con el Enchiridion de Epícteto) y contenido, era el 
primer texto que, junto a las oraciones de Isócrates, se proponía para ser leído y traducido en las clases de griego elemental tal y como se recoge en la Ratio Studiorum (sistema educativo de la Compañía de Jesús). Se atribuía a un filósofo tebano llamado Cebes, discípulo de Sócrates, del siglo $\mathrm{V}$ a. C. aunque en la actualidad la crítica considera que se trata de un texto del siglo I d. C. que, aunque escrito en griego, procede de la época imperial romana.

En ese mismo año aparece La Poética de Aristóteles dada a nuestra lengua castellana por Don Alonso Ordóñez das Seijas y Tobar, Señor de San Payo; añádese nuevamente el texto griego, la versión latina y notas de Daniel Heinsio, y las del Abad Batteux traducidas del francés, y se ha suplido y corregido la traducción castellana por Don Casimiro Flórez Canseco.

Su tercera y última obra dedicada a la traducción fueron Las obras de Xenofonte ateniense que aparecieron en 1781 en dos tomos. Tomo I, La Cyropedia o Historia de la vida y hechos de Cyro el Mayor/ trasladadas de Griego en Castellano por el secretario Diego Gracián, en que se ha añadido el texto Griego, y se ha enmendado la Traducción Castellana por el Licenciado Don Casimiro Flórez Canseco. Tomo II, Historia de la vida y hechos de la entrada de Cyro el Menor en el Asia y de la retirada de los diez mil griegos que fueron con él/ trasladadas de Griego en Castellano por el secretario Diego Gracián, en que se ha añadido el texto Griego, y se ha enmendado la Traducción Castellana por el Licenciado Don Casimiro Flórez Canseco.

Aparte de estas tres obras, Casimiro Flórez Canseco escribió otras dos. Una de ellas quedó inédita. Se trata del Método para enseñar y aprender la lengua griega que el autor realizó a petición de Campomanes en 1783 y que presentó al Consejo. El manuscrito inédito, documento sin duda interesante, es reproducido íntegramente por Concepción Hernando (1975: 330-349). Consta de cuatro capítulos en los que parte de la justificación del estudio de la lengua griega para abordar los aspectos de la pronunciación, la morfología, la sintaxis, la traducción y los autores más adecuados para la misma o su temporalización. 
La última de sus obras, Carta de Antheo Mantuano al maestro Fr. Juan de Cuenca del orden de S. Gerónimo..., tiene una peculiar historia.

En 1789 se publicaba en Madrid, en la imprenta de D. Antonio de Sancha, una Gramática de la Lengua Griega compuesta por fray Juan de Cuenca, de la Orden de San Jerónimo. Se trataba del primer volumen de la obra y estaba claramente patrocinada por Pedro de Campomanes quien, según C. Hernando, realizó cuanto estuvo en su mano "para asegurar su éxito y difusión". Lo que estuvo en su mano fue no solamente realizar la reseña de su publicación sino incluso conseguir que el Consejo la recomendara a la Universidad de Alcalá. La obra no era buena en absoluto pero, además, Flórez Canseco guardaba una extraordinaria fidelidad a la obra de su maestro, el P. Zamora cuya gramática, recuérdese, había sido la causante del increíble enfrentamiento que había tenido lugar en los Reales Estudios de San Isidro el primer año de su restablecimiento.

En 1791, cuando declinaba la figura de Campomanes, se publicó la Carta de Antheo Mantuano al maestro Fr. Juan de Cuenca del orden de S. Gerónimo, etc., etc., etc., en que se hacen ver algunos de los innumerables errores que contiene su primer tomo de gramática griega. Se trataba de un estudio crítico de la Gramática Griega del P. Cuenca, escrito por un autor parapetado tras un seudónimo: Antheo Mantuano. Que tras Antheo Mantuano se encontraba Flórez Canseco fue ya constatado por Menéndez Pelayo en su Biblioteca de Traductores Españoles II (1952: 68) aunque consignara la errónea forma Aristeo en vez de Antheo, que es la correcta. Concepción Hernando (1975: 139) lo confirma y explica el porqué del pseudónimo creado sobre las palabras anzos, flor en la lengua griega, y de Mantua Carpetanorum o, lo que es lo mismo, Madrid.

En su carta, Flórez Canseco “destripa” con argumentos la obra del P. Cuenca ("El escribir una gramática mala -apunta- no tiene disculpa. Es una prueba nada equívoca o de una estúpida ignorancia o, si se quiere más, de un descaro sin ejemplo") de tal manera que Hernando (1975: 141) considera que este opúsculo, “hilarante y destructivo" es “quizá la mejor reseña científica que se haya escrito en castellano". 
La sombra de Pedro Campomanes consiguió, sin embargo, algo sorprendente: hizo secuestrar la edición y que desapareciesen las copias del mercado. De forma que hoy apenas existen ejemplares a pesar de que sabemos que la tirada constó de 500 y que se había publicado con licencia real. Los catálogos de las bibliotecas universitarias apenas nos ofrecen dos: uno de ellos se encuentra en la Universidad Complutense de Madrid; otro puede consultarse en la Universidad de Navarra.

Flórez Canseco fue, sin duda, un académico fiel y comprometido. Tuvo el privilegio de asistir en 1794 a la primera sesión que la Academia celebraba en la que iba a ser su nueva sede ${ }^{25}$, el edificio del Antiguo Estanco del Aguardiente, en la calle Valverde, donde permanecerá exactamente un siglo. $\mathrm{Y}$ se encuentra entre los académicos presentes en la recepción de Arnault, que tiene lugar el 13 de enero de 1801, y es la primera que la Academia depara oficialmente a un literato francés.

Del prestigio que le rodeaba parece ser confirmación el hecho de que, agotadas las ediciones del Quijote de 1782 y 1787, en 1802 la Academia, que había acordado editar de nuevo la obra, nombró una comisión de expertos para realizar el trabajo entre los que se encontraba, junto con Vicente González Arnao y Manuel Abella, Flórez. Ellos propusieron repartir el texto en cinco volúmenes, ajustar la ortografía a las normas de la Academia, suprimir las variantes de la edición valenciana de 1616 o cotejar con las ediciones de Browle (1781) y Pellicer (1797). Pero la situación política de España impediría un trabajo que años después proseguiría Martín Fernández de Navarrete. No obstante, y pese a todo, Flórez Canseco es uno de los académicos que siguieron asistiendo a las sesiones de la Academia, apenas 20 (Zamora, 1999: 451), que tuvieron lugar entre los años 1808 y 1814.

Y, en fin, el nombre de este leonés encabeza la lista de firmantes que agradecen la abolición de la Inquisición con una carta que envían a las Cortes el día 5 de julio de 1813.

\footnotetext{
${ }^{25}$ Hasta entonces las sesiones de la Academia tenían lugar en una dependencia aneja del Palacio Real, la Casa del Tesoro (Zamora, 1999: 53).
} 
Es, sin duda, una lástima que carezcamos de datos biográficos de un hombre al que conocemos poco como persona y sobre el que surgen interesantes interrogantes: ¿Era noble? ¿Tuvo descendencia? ¿Dónde estudió las primeras letras? Apenas si nos consta el nombre de sus padres y el de un sobrino carnal, Estanislao Flórez Canseco, citado por Menéndez Pelayo (1962:68). Una carta (Hernando, 1975: 3554-355) que el propio Casimiro Flórez Canseco le envía el 28 de octubre de 1798 a fray Juan de Soto, en contestación a una petición de este sobre su método de enseñar lengua griega, nos proporciona los dos datos más humanos que sobre él tenemos:

Confieso a Vmd. que si yo fuera fraile (y no he perdido las esperanzas de serlo)[...] Estoy desazonadísimo con unas telarañas que se me han dado en poner delante del ojo derecho, que era el mejor, y yo que valía poco para testigo de vista, gracias a las letras griegas, valgo ya para menos...

El sillón P que ocupó hasta su muerte en Madrid, el 3 de mayo de 1816, estuvo, sin duda, dignísimamente representado en la figura de este leonés, cuarta contribución leonesa a la Academia en su primer siglo de vida.

\section{BIBLIOGRAFÍA}

Andrés, E. (1988): Helenistas españoles del siglo XVII, Madrid, Fundación Universitaria Española.

Andrés, G. (1983): “Los manuscritos de Juan de Ferreras en la Biblioteca Nacional”, Revista Española de Teología, 43: 159-169.

Bordita Grinstein, J. (2002): “Dramaturgia femenina española en la segunda mitad del siglo XVIII y principios del XIX", Dieciocho: Hispanic Enlightenment, Vol. 25, Nº. 2: 195-218.

Cantón, I. y Prieto, M. (1997): La cátedra de latín de Lois, León, Universidad de León.

Cotarelo Mori, E. (1914): “La fundación de la Real Academia Española y su primer director, Don Juan Manuel F. Pacheco, marqués de Villena", Boletín de la RAE, año I, tomo I: 4-38 y 89-127.

Flórez Canseco, C. (1778): El Sueño de Luciano Samosatense, que es la Vida de Luciano: Y la Tabla de Cebes, philosofo tebano en griego y español. Ilustradas con notas y la 
Análisis Gramatical para provecho de los que se aplican a la Lengua Griega, por el Lic.

D. Casimiro Flórez Canseco. Madrid, Impr. de Antonio de Sancha.

Flórez Canseco, C. (1778): La Poética de Aristóteles dada a nuestra lengua castellana por Don Alonso Ordóñez das Seijas y Tobar, Señor de San Payo; añádese nuevamente el texto griego, la versión latina y notas de Daniel Heinsio, y las del Abad Batteux traducidas del francés, y se ha suplido y corregido la traducción castellana por Don Casimiro Flórez Canseco. Madrid, Impr. de Antonio de Sancha.

Flórez Canseco, C. (1781): Las obras de Xenofonte ateniense. Tomo I, La Cyropedia o Historia de la vida y hechos de Cyro el Mayor/trasladadas de Griego en Castellano por el secretario Diego Gracián, en que se ha añadido el texto Griego, y se ha enmendado la Traducción Castellana por el Licenciado Don Casimiro Flórez Canseco. Madrid, Imprenta Real de la Gazeta.

Flórez Canseco, C. (1781): Las obras de Xenofonte ateniense. Tomo II, Historia de la vida y hechos de la entrada de Cyro el Menor en el Asia y de la retirada de los diez mil griegos que fueron con él/ trasladadas de Griego en Castellano por el secretario Diego Gracián, en que se ha añadido el texto Griego, y se ha enmendado la Traducción Castellana por el Licenciado Don Casimiro Flórez Canseco. Madrid, Imprenta Real de la Gazeta.

Gutiérrez Torrecilla y Ballesteros Torres (1998): Cátedras y catedráticos de la Universidad de Alcalá (1508-1786), Madrid, Universidad de Alcalá.

Gil L. (1975): “Una poesía juvenil desconocida de Meléndez Valdés”, Prohemio, V: 6574.

Hernando, C. (1975): Helenismo e Ilustración (El griego en el siglo XVIII español), Madrid, Fundación Universitaria Española.

Lázaro Carreter, F. (1981): Estudios de Lingüística, Madrid, Crítica.

Marcos Segovia, J. (1957): Algunas efemérides bañezanas, León.

Martínez García, F. (1982): Historia de la Literatura Leonesa, León, Everest.

Menéndez Pelayo, M. (1962): Biblioteca de Traductores Españoles II, Madrid, CSIC.

Mingote y Tarazona, P. (1978): Varones ilustres de la provincia de León, León, Nebrija. Nasarre y Ferriz, B. (1735): Elogio histórico de don Juan de Ferreras. Madrid, Imprenta de la RAE. 
Sánchez Espinosa, G. (2002): “La obra del naturalista Guillermo Bowles y la política editorial del gobierno ilustrado", Dieciocho: Hispanic Enlightenment, Vol. 25, No 2: $255-280$.

Simón Díaz, J. (1992): Historia del Colegio Imperial de Madrid. Del Estudio de la Villa al Instituto San Isidro. Madrid, Instituto de Estudios Madrileños.

Zamora Vicente, A. (1999): Historia de la Real Academia Española, Madrid, Espasa Calpe. 